\title{
Thermal stability of the high-N solid-solution layer on stainless steel
}

\author{
Orhan Öztürk $^{\mathrm{a} *}$, D.L. Williamson ${ }^{\mathrm{b}}$ \\ ${ }^{a}$ Department of Physics, Izmir Institute of Technology, Izmir 35487, Turkey \\ ${ }^{\mathrm{b}}$ Physics Department, Colorado School of Mines, Golden, CO 80401, USA
}

\begin{abstract}
Low-energy, high-flux $\mathrm{N}$ ion implantation into austenitic stainless steel held at approximately $400{ }^{\circ} \mathrm{C}$ results in dramatic improvements in the tribological properties due to sufficiently large $\mathrm{N}$ layer thicknesses and high- $\mathrm{N}$-content solid solution phase, $\gamma_{\mathrm{N}}$. In this paper, post-ion beam processing via isothermal annealing of a low-energy $(0.7 \mathrm{keV}), \mathrm{high}-\mathrm{flux}\left(2.5 \mathrm{~mA} / \mathrm{cm}^{2}\right) \mathrm{N}$ implanted fcc 304 stainless steel held at $400{ }^{\circ} \mathrm{C}$ has been investigated by Mössbauer spectroscopy and X-ray diffraction (XRD). Post-implantation annealing at $400{ }^{\circ} \mathrm{C}$ demonstrated the metastability and showed that the magnetic $\gamma_{\mathrm{N}}$ produced at lower ion energies and higher fluxes transformed systematically to a paramagnetic $\gamma_{\mathrm{N}}$ phase with less $\mathrm{N}$ content and less lattice expansion, thereby destabilizing the magnetic state of $\gamma_{N}$. The isothermal annealing results in much thicker $\gamma_{\mathrm{N}}$ layers but with less $\mathrm{N}$ in solid solution due to the $\mathrm{N}$ diffusion into the substrate. Based on the XRD data, the $\mathrm{N}$ diffusivity under isothermal annealing conditions is found to be $D=2 \times 10^{-13} \mathrm{~cm}^{2} / \mathrm{s}$ at $400{ }^{\circ} \mathrm{C}$, consistent with a model which explains that the trapping by $\mathrm{Cr}$ atoms in the stainless steel becomes more effective when $\mathrm{N}$ contents are low relative to the Cr concentration $(\sim 19$ at.\% in 304 stainless steel).
\end{abstract}

(c) 2002 Elsevier Science B.V. All rights reserved.

Keywords: Diffusion; Nitrogen implantation; Ferromagnetism; Stainless steel; Mössbauer spectroscopy; X-Ray diffraction

\section{Introduction}

Low-energy $(\leq 2 \mathrm{keV})$, high-flux (a few $\left.\mathrm{mA} / \mathrm{cm}^{2}\right)$ nitrogen ion implantation into 304 stainless steel (SS) at $400{ }^{\circ} \mathrm{C}$ is known to generate a metastable, fcc, interstitial, high-N content phase $\left(\gamma_{\mathrm{N}}\right)$ in the implanted layer with both magnetic and paramagnetic characteristics [1-5]. Under such conditions, the $\gamma_{\mathrm{N}}$ layers are found to have $\mathrm{N}$ layer depths several microns thick and $\mathrm{N}$ contents approaching 30 at.\%. Such layers have technological importance due to their high strength (microhardness as high as $20 \mathrm{GPa}$ ) and good corrosion resistance [3].

One important characteristic of the $\gamma_{\mathrm{N}}$ phase is its metastability, which has been investigated under highand low-energy $\mathrm{N}$ beam conditions, low-temperature plasma nitriding conditions, as well as under thermal annealing studies (post-ion and post-plasma nitriding processing). The metastability has been established based on annealing experiments, which show the $\gamma_{\mathrm{N}}$

\footnotetext{
*Corresponding author. Tel. +90-932-498-7513; fax: +90-232498-7509.

E-mail address: oozturk@likya.iyte.edu.tr (O. Öztürk).
}

phase gradually decomposes upon annealing at $400{ }^{\circ} \mathrm{C}$ [6]. It has also been investigated in the presence of lowenergy $\mathrm{N}$ ion beam processing conditions at higher substrate temperatures (above approx. $450{ }^{\circ} \mathrm{C}$ ) which leads to a phase separated mixture of bcc-FeNi and fcc$\mathrm{CrN}$ [2]. Lower implantation temperatures $(\sim 220-350$ $\left.{ }^{\circ} \mathrm{C}\right)$ result in hexagonal nitride, $\varepsilon-(\mathrm{Fe}, \mathrm{Cr}, \mathrm{Ni}){ }_{2+} \mathrm{N}$ with both paramagnetic and magnetic characteristics $[6,7]$.

The metastability of the $\gamma_{\mathrm{N}}$ phase has also been investigated both in the presence and absence of lowtemperature plasma nitriding conditions. One such study [8], a systematic investigation of the thermal stability of the $\gamma_{\mathrm{N}}$ phase as a function of both temperature (200$\left.600{ }^{\circ} \mathrm{C}\right)$ and time $(20-3000 \mathrm{~h})$, found that the $\gamma_{\mathrm{N}}$ phase is thermodynamically metastable due to its extremely high solubility of nitrogen $(\mathrm{N}$ content reported in the plasma nitrided state was $\sim 22$ at. $\%$, which is actually quite low in comparison to that found with our lowenergy, high-flux $\mathrm{N}$ ion beam processing conditions, $\sim 30$ at. $\%$ ).

The $\gamma_{\mathrm{N}}$ phase stability needs further investigation since under the low-energy $\mathrm{N}$ implantation conditions the top surface of fcc-SS becomes magnetic due to very 
high $\mathrm{N}$ contents and residual stresses [3,4]. Having a magnetic $\gamma_{N}$ layer on a non-magnetic substrate $(\gamma$ phase) in addition to its high strength may have other useful applications. This aspect of the $\gamma_{N}$ phase (i.e. its magnetic character) somehow has not been an important issue, even though this phase has now been studied extensively by various research groups. Prior to our work, there were only few studies related to the magnetic nature and stability of this phase $[9,10]$, one of which (an ion nitriding study of $304 \mathrm{SS}$ at $400{ }^{\circ} \mathrm{C}$ ) found that the nitrided layer was composed of the $\gamma_{\mathrm{N}}$ phase and was of ferromagnetic nature [9], and the other (hydrogen incorporation into fcc-SS by cathoding charging method) found a high-H-phase (this phase is referred to as the fcc hydride phase and is a high solid solution phase similar to the $\gamma_{\mathrm{N}}$ phase) which had the magnetic properties of a soft magnetic material [10]. In our research, the magnetic $\gamma_{\mathrm{N}}$ was also found to be ferromagnetically soft in nature, and to be distributed in the highest concentration (top-most) region of the implanted layer. The $\gamma_{\mathrm{N}}$ transformed to the paramagnetic state deeper into the layer as the $\mathrm{N}$ concentration and degree of lattice expansion decreased [3]. More recently, magnetic force microscopy studies have revealed a micronsized, maze-like magnetic domain structure for the ferromagnetic $\gamma_{N}[1,11]$.

Of ongoing interest, and of relevance to the magnetic and phase stability, have been the $\mathrm{N}$ diffusion depth and the associated mechanism(s), as well as the nearly rectangular shape of the $\mathrm{N}$ concentration profiles for the low-energy, high-flux beam conditions. An experiment coupled with a qualitative model [12] provided direct evidence of the critical role played by the substrate element $\mathrm{Cr}$ in the formation of the $\gamma_{\mathrm{N}}$ phase and the retention of high $\mathrm{N}$ contents in the same phase along with an explanation of non-error function, reaction frontlike $\mathrm{N}$ concentration profiles. As shown in Parascandola et al. [13], a more careful analysis of the $\mathrm{N}$ diffusivity including trapping/detrapping of the $\mathrm{N}$, presumably at the $\mathrm{Cr}$ atoms, yielded a reasonable explanation of the non-error function shape of the $\mathrm{N}$ profiles (some experimental depth profiles are of approximately rectangular shape).

In this paper, we present a post-ion-implantation annealing study of a low-energy, high-flux $\mathrm{N}$ ion implanted 304 SS to examine the thermal stability of the implantation-induced near-surface phases, both magnetic and paramagnetic $\gamma_{\mathrm{N}}$, and to induce further diffusion of the $\mathrm{N}$ in the absence of the ion beam. In addition, further diffusion of the $\mathrm{N}$ in the absence of the ion beam will be investigated to shed more light on the $\mathrm{N}$ diffusion behavior under the low-energy $\mathrm{N}$ ion beam conditions.

\section{Experimental}

Austenitic fcc AISI 304 SS with elemental compositions of $70 \% \mathrm{Fe}, 19 \% \mathrm{Cr}, 7 \% \mathrm{Ni}, 0.4 \% \mathrm{C}, 2 \% \mathrm{Mn}, 2 \%$ $\mathrm{Si}, 0.08 \% \mathrm{P}$, and $0.05 \% \mathrm{~S}$, (all in at.\%), was the base specimen into which $\mathrm{N}$ was implanted. The specimen was a square plate $2.5 \mathrm{~cm}$ on the side and $0.2 \mathrm{~cm}$ thick, and its average polycrystalline grain size, obtained by metallography, was $\sim 50 \mu \mathrm{m}$. Before implantation the specimen was polished to mirror-like quality with a mean surface roughness of approximately $0.02 \mu \mathrm{m}$ based on surface profilometry. The following implantation conditions were implemented: (1) ion beam energy of $0.7 \mathrm{keV}$; (2) ion beam current density of $2.5 \mathrm{~mA}$ / $\mathrm{cm}^{2}$; (3) substrate temperature of $400{ }^{\circ} \mathrm{C}$ (measured by a thermocouple attached to the back of the specimen and controlled by a combination of ion beam heating and a substrate heater); and (4) implantation time of 10 $\min$.

After implantation, the specimen was subjected to isothermal annealing at $400{ }^{\circ} \mathrm{C}$ for increasing times up to $36 \mathrm{~h}$. The annealings were carried out under constant flow of high purity $\mathrm{He}$ in a quartz tube furnace with a temperature stability of $\pm 1{ }^{\circ} \mathrm{C}$. The temperature was measured with an alumel-chromel (type K) long rod thermocouple placed adjacent to the sample.

Near-surface phases, $\mathrm{N}$ contents, and the $\mathrm{N}$ layer thicknesses of the as-implanted and annealed specimen after each anneal step (total of five steps) were made by conversion electron Mössbauer spectroscopy (CEMS) and symmetric (Bragg-Brentano) X-ray diffraction (XRD). In addition, conversion X-ray Mössbauer spectroscopy (CXMS) was used to provide further information on the depth distributions of the implanted and annealed layer phases extending deeper into the substrate. The XRD data for the as-implanted state and after annealing at increasing times were analyzed quantitatively to extract average $\mathrm{N}$ contents and average $\mathrm{N}$ depths. More details related to quantitative XRD can be found in Öztürk and Williamson [3].

\section{XRD results and discussion}

Fig. 1 shows the XRD results for the as-implanted state $(0 \mathrm{~h})$ and after $400{ }^{\circ} \mathrm{C}$ annealing at increasing times. The fcc substrate (304 SS) peaks are labeled as $\gamma$ and the implantation induced ones as $\gamma_{N}$, in this figure. Note that the square root of the intensity is plotted to reveal more clearly the weaker peaks. The XRD results for the as-implanted state are consistent with those of other low-energy, high-flux implanted SS samples $[1,3,4]$ in that the $\gamma_{N}(200)$ peak is shifted more than the $\gamma_{N}(111)$ relative to the (200) and (111) substrate, $\gamma$ peaks. Also, the implanted integrated layer thickness (see Öztürk and Williamson [3] for details as to how the $\gamma_{\mathrm{N}}$ layer thicknesses and $\mathrm{N}$ contents are calculated) associated with (200) oriented grains, $L_{200}$, 


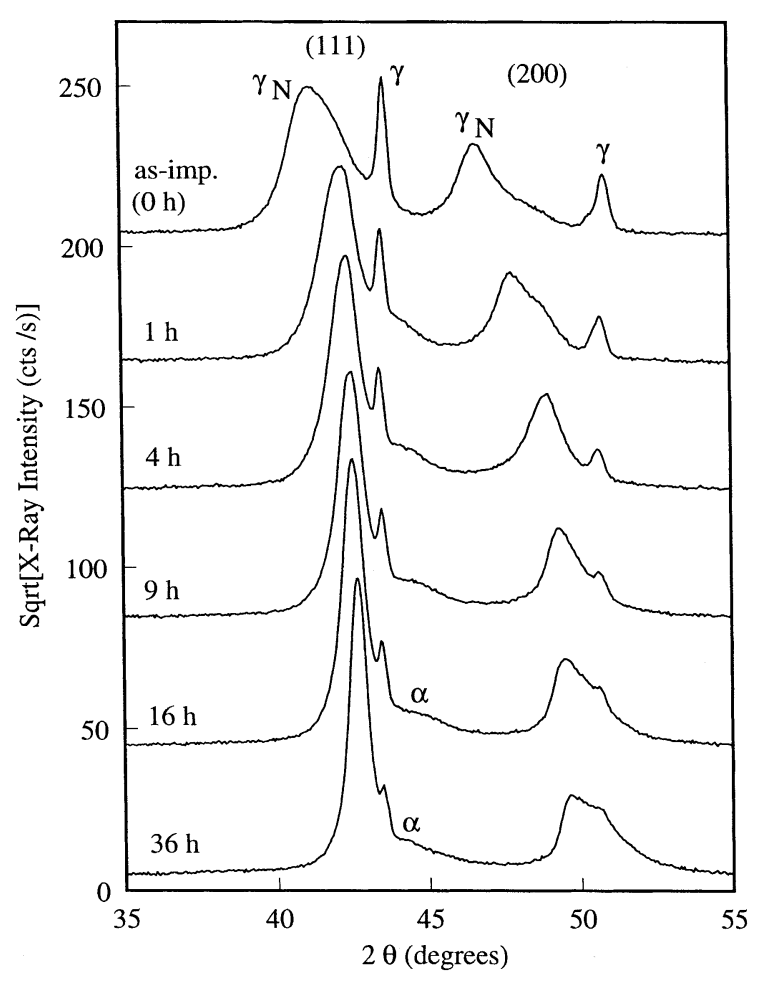

Fig. 1. XRD data for the as-implanted sample and after $400{ }^{\circ} \mathrm{C}$ anneal at increasing times. The (111) and (200) $\gamma-\gamma_{\mathrm{N}}$ pairs indicated. The $\alpha$ is the annealing -induced phase attributed to small bcc $\alpha-(\mathrm{Fe}, \mathrm{Ni})$ precipitates.

is significantly larger than $L_{111}$. Based on the lattice constant analysis of the $\gamma_{\mathrm{N}}$ phase, and the relative integrated intensities of the $\gamma$ and $\gamma_{\mathrm{N}}$ peaks [3], 23 and 36 at.\% $\mathrm{N}$ are distributed to depths of 1.5 and $1.9 \mu \mathrm{m}$ in the (111)- and (200)-oriented grains, respectively. These results clearly suggest larger $\mathrm{N}$ contents and larger $\mathrm{N}$ penetration in the (200)-oriented grains.

The $1 \mathrm{~h}$ anneal at $400{ }^{\circ} \mathrm{C}$ causes dramatic shifts in the $\gamma_{\mathrm{N}}$ peak positions relative to the $\gamma$ peaks (the $\gamma_{\mathrm{N}}$ peak positions move to higher angles). The XRD data also show increases in the relative intensities of the $\gamma_{N}$ peaks compared to the substrate $\gamma$ peaks, consistent with a thickening of the $\gamma_{\mathrm{N}}$ layer. According to the XRD analysis, $\mathrm{N}$ contents of 13 and 25 at. $\%$ are distributed to 2 and $2.4 \mu \mathrm{m}$ depths in the (111) and (200) grains, respectively. Comparison of these values with those of the as-implanted state clearly demonstrates significant $\mathrm{N}$ diffusion into the substrate.

The effect of longer annealing is the continued $\mathrm{N}$ diffusion into the substrate as can be inferred from the increases in the relative intensities of both the (111) and $(200) \gamma_{\mathrm{N}}$ peaks relative to the (111) and (200) substrate, $\gamma$ peaks. The increase in the $\mathrm{N}$ depth in the (111) and (200) grains is compensated by the further decrease in the $\mathrm{N}$ contents in the same grains as seen by the reduced separations in the (111)-(200) $\gamma-\gamma_{\mathrm{N}}$ pairs. After the $36-\mathrm{h}$ anneal at $400{ }^{\circ} \mathrm{C}$, XRD analysis gives $\mathrm{N}$ contents of 8.2 and 8.7 at.\% distributed to depths of 3.2 and $3.9 \mu \mathrm{m}$ in the (111) and (200) grains, respectively.

The XRD data also show the existence of a rather broad peak labeled $\alpha$ in Fig. 1. In fact, this peak first appears after the $1 \mathrm{~h}$ anneal step and nearly remains the same (in intensity and broadness) following the subsequent anneal steps as seen from Fig. 1. This broad peak is believed to be due to small precipitates of bcc $\alpha$ $(\mathrm{Fe}, \mathrm{Ni})$. This phase was also observed as a result of $400{ }^{\circ} \mathrm{C}$ annealing $(64 \mathrm{~h})$ of a paramagnetic $\varepsilon$-nitride phase that was produced by $\mathrm{N}$ implantation of a $304 \mathrm{SS}$ at $210{ }^{\circ} \mathrm{C}$ [6]. However, the observation of $\alpha$ in the latter experiment was much more obvious in that the XRD-detected (110) $\alpha$ peak was sharper and a higher order $\alpha$ peak $\left[(200)\right.$ near $\left.65^{\circ}\right]$ was also clear. The broad nature of the $\alpha$ peak observed here is attributed to the small size of the precipitates.

Higher angle XRD data associated with higher $(h k l)$ $\gamma-\gamma_{\mathrm{N}}$ pair peaks indicate that the annealing at increasing times clearly produces observable shifts and sharpening of the (220), (311) and (222) as-implanted $\gamma_{N}$ peaks. These qualitative trends may be interpreted as decreases and increases in the $\mathrm{N}$ contents and the $\mathrm{N}$ depths, respectively (due to the $\mathrm{N}$ diffusion into the substrate) in the (220), (311) and (222) oriented grains. Quantitative analyses of these patterns yield the concentrations listed in Table 1, together with a summary of the results discussed above. As can be seen from this table, the decreases in the (111) and (200) N contents are steep at the beginning but show saturation behavior at longer annealing times and this seems to correlate well with the maximum nitrogen solubility in $\gamma$-Fe [14]. The (220), (311) and (222) N contents also show a slow, but a continuous decrease as the annealing time increases with corresponding increases in the layer thicknesses.

Table 1

XRD-determined $\mathrm{N}$ contents for an $(h k l)$ plane, $C_{h k l}$ (at.\%), and $\mathrm{N}$ layer thicknesses, $L_{h k l}(\mu \mathrm{m})$, based on various grain orientations parallel to the surface of the sample

\begin{tabular}{lllllllll}
\hline $\begin{array}{l}\text { Anneal } \\
\text { time } \\
\text { (h) }\end{array}$ & $C_{111}$ & $C_{200}$ & $C_{220}$ & $C_{311}$ & $C_{222}$ & $L_{111}$ & $L_{200}$ & $L_{220}$ \\
\hline 0 & $23(21)$ & $36(31)$ & - & - & - & 1.5 & 1.9 & - \\
1 & $13(11)$ & $25(20)$ & 9.6 & 13 & 14 & 2.0 & 2.4 & 1.0 \\
4 & 9.6 & 14 & 8.4 & 10 & 12 & 2.3 & 2.8 & 1.2 \\
9 & 8.8 & 10 & 7.9 & 8.4 & 10 & 2.5 & 2.9 & 1.6 \\
16 & 8.4 & 9.3 & 7.1 & 7.5 & 9.2 & 2.7 & 3.7 & 1.7 \\
36 & 8.2 & 8.7 & 6.4 & 6.5 & 7.8 & 3.2 & 3.8 & 2.2 \\
\hline
\end{tabular}

Due to the broad and weak nature of the Bragg peaks associated with the as-implanted state $(0 \mathrm{~h})$, the $\mathrm{N}$ contents and layer thicknesses belonging to the (200), (311) and (222) grain orientations are not available. The values in parentheses are the $\mathrm{N}$ contents corrected for residual stress operating in the $\mathrm{N}$-implanted layer, assumed to be 2 $\mathrm{GPa}[3]$. 


\section{4. $\mathbf{N}$ diffusion analysis}

The diffusion coefficients for $\mathrm{N}$ in 304 SS were estimated from the $\mathrm{N}$ depths listed in Table 1. The anneal times were selected in anticipation of a rootmean-square diffusion distance being proportional to $(D t)^{1 / 2}$, where $D$ is the diffusion coefficient and $t$ is the anneal time. The $\mathrm{N}$ diffusivities in the (111), (200) and (220) grains, calculated under the assumption $L=$ $(D t)^{1 / 2}$, are found to be $2.0 \times 10^{-13}, 3.0 \times 10^{-13}$ and $1.7 \times 10^{-13} \mathrm{~cm}^{2} / \mathrm{s}$, respectively. Thus, the values suggest that the thermal mobilities of $\mathrm{N}$ in the (111), (200) and (220) oriented grains are nearly the same. The average $D$ found here, $2.2 \times 10^{-13} \mathrm{~cm}^{2} / \mathrm{s}$, is one order of magnitude higher than that obtained from an earlier annealing study [6]. The higher $\mathrm{N}$ diffusivity found in this experiment might be related to the fact that the initial $\gamma_{N}$ (the as-implanted state) layer had a much larger $\mathrm{N}$ content (an average of $\sim 26$ at.\% after the stress correction [3]) than that noted in Öztürk and Williamson [6]. The results here suggest that the $\mathrm{N}$ diffusivity depends on the $\mathrm{N}$ content. The $D$-value found here is also a few orders of magnitude greater than those in the literature based on thermal diffusion of $\mathrm{N}$ in $\mathrm{fcc}$ SS. A temperature annealing study of a low-dose, 40 $\mathrm{keV} \mathrm{N}$ implanted $316 \mathrm{SS}$, based on a nuclear resonance broadening method, found $D$ to be approximately $5 \times 10^{-16} \mathrm{~cm}^{2} / \mathrm{s}$ at $400{ }^{\circ} \mathrm{C}$ [15]. However, a similar study by RBS of a MeV N implanted $304 \mathrm{SS}$ found an average $D$ of $5 \times 10^{-15} \mathrm{~cm}^{2} / \mathrm{s}$ at $400{ }^{\circ} \mathrm{C}$ [16].

The smallness of the $D$ values in Refs. $[15,16]$ as compared to the one found in this experiment is likely due to the differences in the $\mathrm{N}$ contents of the $\mathrm{N}$ implanted specimens and the role played by the substrate element Cr. The specimens in Hirvonen and Anttila [15] and Fink et al. [16] were implanted with an $\mathrm{N}$ dose of approximately $10^{17}$ ions $/ \mathrm{cm}^{2}$, while in this experiment, the $\mathrm{N}$ dose was higher by at least two orders of magnitude. As a consequence, Hirvonen and Anttila [15] reported only a few at.\% $\mathrm{N}$ in solution in comparison to 26 at. $\%$ here.

It is well known that the substrate element $\mathrm{Cr}$ has a trapping effect on the migration of N in 304 SS (or 316 SS). Past research indicates that the reduction in the mobility of $\mathrm{N}$ is due to the selective bonding between $\mathrm{N}$ and $\mathrm{Cr}$ [17]. The trapping by $\mathrm{Cr}$ is more effective when the $\mathrm{N}$ contents are low as compared to the relatively high $\mathrm{Cr}$ concentration ( $\sim 19$ at.\% in $304 \mathrm{SS}$ ). So, the higher $D$-value in this experiment is attributed to the larger $\mathrm{N}$ contents, which are less affected by the $\mathrm{Cr}$ trapping (many of the $\mathrm{Cr}$ traps are already occupied by $\mathrm{N}$ ).

Even though the $D$-value found here as a result of the annealing experiment is higher than the literature values, it is still too small to explain the deep penetration effect observed in low-energy, high-flux $\mathrm{N}$ implanted

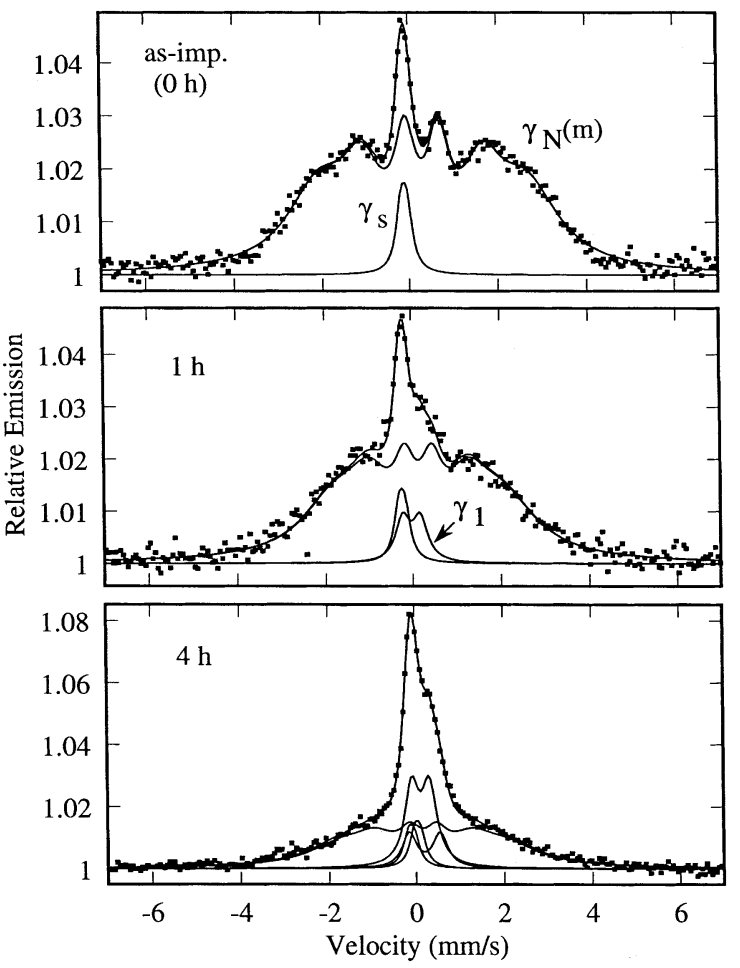

Fig. 2. CEMS data for the as-implanted sample and after $400{ }^{\circ} \mathrm{C}$ anneal at increasing times. The paramagnetic substrate phase, $\gamma_{s}$, contributes to the as-implanted $(0 \mathrm{~h})$ CEMS resonance.

$304 \mathrm{SS}$ at $400{ }^{\circ} \mathrm{C}[1-4]$. In the latter case, the effective diffusion constant is estimated to be $\sim 10^{-11} \mathrm{~cm}^{2} / \mathrm{s}$ based on $\gamma_{\mathrm{N}}$ thickness growth modeled with a simple diffusion equation including sputtering [1]. Much more detailed explanation about the enhanced $\mathrm{N}$ diffusivity under the low-energy, high-flux implantation conditions, in particular the role played by the high-flux beam and the substrate element $\mathrm{Cr}$ in forming the $\gamma_{\mathrm{N}}$ and affecting the $\mathrm{N}$ concentration profile, is explained elsewhere [13]. The $D$-value obtained here is also smaller than that of $\mathrm{N}$ diffusion in pure fcc $\gamma$-Fe, which is on the order of $10^{-11} \mathrm{~cm}^{2} / \mathrm{s}$ based on extrapolation of high temperature data to $400{ }^{\circ} \mathrm{C}$ [4].

\section{CEMS results and discussion}

Figs. 2 and 3 show the CEMS results for the asimplanted sample $(0 \mathrm{~h})$ and after $400{ }^{\circ} \mathrm{C}$ annealing at increasing times. The CEMS spectrum of the as-implanted sample $(0 \mathrm{~h})$ is clearly dominated by the magnetic $\gamma_{N}$, designated $\gamma_{N}(m)$, which is the dominant phase for low-energy, high-flux implanted samples $[1,3,4]$. Based on the XRD results [3] this phase is also attributed to an fcc structure with $\mathrm{N}$ in octahedral sites but with larger $\mathrm{N}$ contents than the paramagnetic $\gamma_{\mathrm{N}}$ phase, $\gamma_{\mathrm{N}}(\mathrm{p})$. Large lattice expansions due to large $\mathrm{N}$ contents and residual stresses in the top-most implanted layer are believed to be responsible for the formation of the 


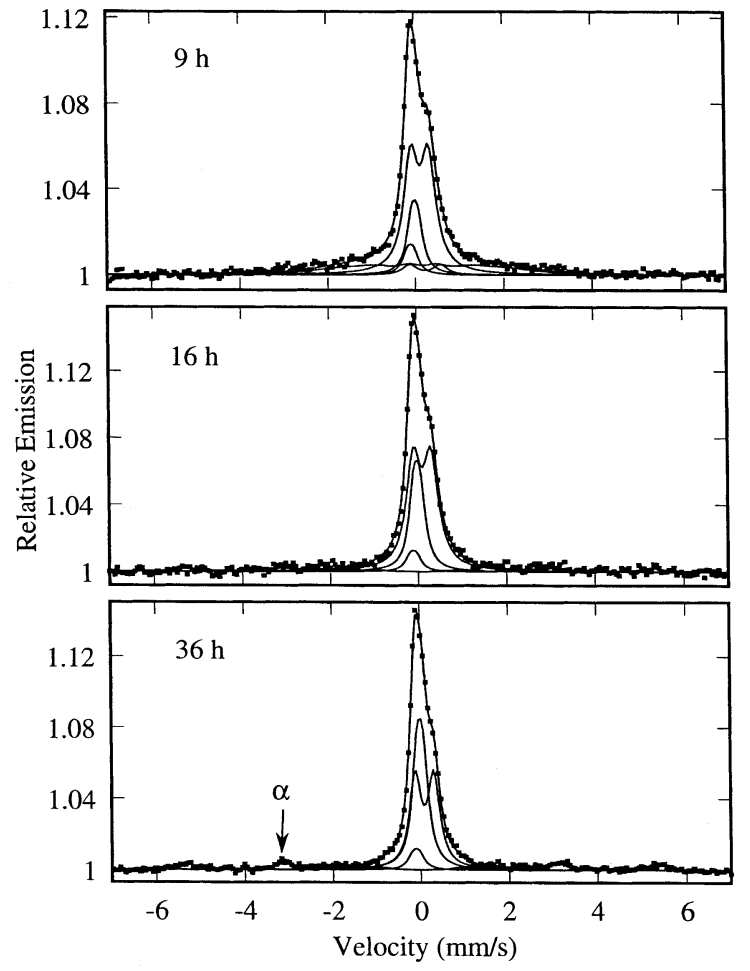

Fig. 3. CEMS data after $400{ }^{\circ} \mathrm{C}$ anneal at increasing times of 9,16 and $36 \mathrm{~h}$, respectively. The weak magnetic component, $\alpha-(\mathrm{Fe}, \mathrm{Ni})$, fitted with six Lorentzian lines, is indicated by a six-line stick diagram.

magnetic phase. The broad nature of the resonance signal is similar to those of the other low-energy, highflux implanted samples [3,4] and is due to variations in the local $\mathrm{N}, \mathrm{Cr}$, Ni environments around $\mathrm{Fe}$. An average hyperfine field of $14 \mathrm{~T}$ was obtained from the distribution fit of the CEMS magnetic resonance. The fraction of the magnetic resonance is $95 \%$ and this result indicates that the top-most implanted layer $(\sim 0.1 \mu \mathrm{m}$, which is the effective probe depth of CEMS) is $100 \%$ magnetic since approximately $6 \%$ of the total CEMS resonance signal is attributed to the paramagnetic substrate phase [18], $\gamma$-SS (labeled as $\gamma_{s}$ in Fig. 2).

The CEMS spectrum after the $1 \mathrm{~h}$ anneal at $400{ }^{\circ} \mathrm{C}$ still indicates the $\gamma_{\mathrm{N}}(\mathrm{m})$ to be the main phase within the top annealed layer $(\sim 0.1 \mu \mathrm{m})$ with only a small fraction of the as-implanted $\gamma_{\mathrm{N}}(\mathrm{m})$ phase $(8 \%)$ transforming into the paramagnetic $\gamma_{\mathrm{N}}$ phase labeled as $\gamma_{1}$ (attributed to the $\mathrm{Fe}$ atoms with one or two nearestneighbor $\mathrm{N}$ atoms). Based on the results of another sample [3] implanted under similar conditions to the one in this study the relatively large fraction of the $\gamma_{N}(m)$ phase suggests the top annealed layer must be under still large lattice expansions (due to high $\mathrm{N}$ contents and accompanying residual stresses). However, the XRD data show significant reductions in the $\gamma_{\mathrm{N}}$ lattice constants resulting in significantly reduced $\mathrm{N}$ contents based on both the (111) and (200) planes. This can be explained by the fact that the $\mathrm{N}$ content obtained by XRD is averaged over a much larger depth than probed by CEMS, so the $\mathrm{N}$ contents must be still high at the top annealed layer probed by CEMS. The apparent high $\mathrm{N}$ content in the top annealed layer $(\sim 0.1 \mu \mathrm{m})$ might also be enhanced by the $\mathrm{N}$ trying to diffuse out the surface since the XRD data after the $1 \mathrm{~h}$ anneal indicates the loss of N. In fact, as can be calculated from Table 1 data, the decrease in the retained $\mathrm{N}$ $\left(\sim C_{h k l} L_{h k l} \rho\right.$, where $\rho$ is the matrix atomic density) supports the latter idea. However, this apparent decrease in the retained $\mathrm{N}$ dose might be explained by a residual stress relaxation, i.e. the $\mathrm{N}$ contents are overestimated at earlier anneal times due to effects of high compressive stresses [3]. The out (or back) diffusion has also been found to be quite significant for the low-energy, highflux as-implanted specimens [2].

The effect of further annealing (4 and $9 \mathrm{~h}$ ) is to destabilize the magnetic state of the $\gamma_{\mathrm{N}}$ by transforming it into the paramagnetic state, as can be seen by the decreases in the relative fraction of the $\gamma_{N}(\mathrm{~m})$ phase. This transformation correlates quite well with the XRD

Table 2

Mössbauer (CEMS) hyperfine parameters and resonance fractions as a function of anneal time at $400{ }^{\circ} \mathrm{C}$

\begin{tabular}{|c|c|c|c|c|c|c|c|c|c|c|}
\hline \multirow{3}{*}{$\begin{array}{l}\text { Anneal } \\
\text { time } \\
\text { (h) }\end{array}$} & \multicolumn{10}{|l|}{ Phases } \\
\hline & \multicolumn{3}{|l|}{$\gamma_{N}(\mathrm{~m})$} & \multicolumn{2}{|l|}{$\gamma_{0}$} & \multicolumn{2}{|l|}{$\gamma_{1}$} & \multirow{2}{*}{$\frac{\gamma_{2}}{F}$} & \multicolumn{2}{|l|}{$\alpha$} \\
\hline & $\delta$ & $H$ & $F$ & $\delta$ & $F$ & $\delta$ & $F$ & & $H$ & $F$ \\
\hline 0 & 0.293 & 14.7 & 95 & - & - & - & - & - & - & - \\
\hline 1 & 0.271 & 12.1 & 87 & - & - & 0.108 & 7 & - & - & - \\
\hline 4 & 0.167 & 11.7 & 56 & 0.033 & 6 & 0.109 & 22 & 10 & - & - \\
\hline 9 & $0.169(f)$ & $11.7(f)$ & 22 & -0.009 & 15 & 0.112 & 52 & 5 & - & - \\
\hline 16 & - & - & - & -0.017 & 28 & 0.105 & 60 & - & 32.9 & 7 \\
\hline 36 & - & - & - & -0.009 & 41 & 0.090 & 43 & - & 33.9 & 10 \\
\hline
\end{tabular}

All measurements were made at room temperature. $\delta$ is the isomer shift (relative to $\alpha$-Fe) in $\mathrm{mm} / \mathrm{s}$, and $H$ is the hyperfine field in Tesla. $F$ is the relative resonance area fraction in percent. $f$ in parentheses indicates that the parameter was fixed. The paramagnetic $\gamma_{\mathrm{N}}$ is composed of the sub-resonances $\gamma_{0}, \gamma_{1}$ and $\gamma_{2}$ (due to various Fe sites with various $\mathrm{N}$ environments) as explained by Öztürk and Williamson [3]. 
data which show a thicker $\gamma_{\mathrm{N}}$ layer with less $\mathrm{N}$ in solid solution and less lattice expansion. The effect of the annealing on the destabilization of the $\gamma_{N}(\mathrm{~m})$ phase can also be seen in the Mössbauer parameters as listed in Table 2 . This table clearly shows that both the internal field $(H)$ and the isomer shift $(\delta)$ decrease as the anneal time increases and this is consistent with reductions in lattice expansion and less $\mathrm{N}$ in solution [3].

The paramagnetic $\gamma_{\mathrm{N}}$ resonance is composed of the sub-resonances $\gamma_{0}, \gamma_{1}$ and $\gamma_{2}$ (due to Fe sites with various $\mathrm{N}$ environments) as described in detail in Öztürk and Williamson [3]. Table 2 also shows the Mössbauer parameters of these components as a function of anneal time. From this table it is seen that both CEMS fractions belonging to $\gamma_{1}$ and $\gamma_{0}$ components increase as function of anneal time. The increase in the $\gamma_{0}$ component may be interpreted as $\mathrm{N}$ diffusion into the substrate leaving lower $\mathrm{N}$ contents near the surface, such that more $\mathrm{Fe}$ sites without nearest-neighbor $\mathrm{N}$ now exist. The increase in the relative fraction of the $\gamma_{1}$ component, up to $16 \mathrm{~h}$, coupled with the decrease in the $\gamma_{\mathrm{N}}(\mathrm{m})$ fraction, clearly illustrates the transformation taking place between the two states of the $\gamma_{\mathrm{N}}$ phase. After $36 \mathrm{~h}$ annealing, the fraction of the $\gamma_{1}$ decreases while the $\gamma_{0}$ fraction increases consistent with $\mathrm{N}$ diffusion out of the top annealed layer.

The CEMS spectrum after the $16 \mathrm{~h}$ anneal also reveals a weak magnetic component attributed to a bcc $(\alpha)$ phase, which becomes more apparent after $36 \mathrm{~h}$ as indicated in Fig. 3. Table 2 shows that the hyperfine field of the $\alpha$ phase slightly increases going from 16 to $36 \mathrm{~h}$ of annealing, but in both cases the field value is much larger than that of a 19 at.\% $\mathrm{Cr} \alpha$-phase alloy [19]. This finding can be explained by $\mathrm{Cr}$ segregation taking place in the surface layer resulting in $\alpha-(\mathrm{Fe}, \mathrm{Ni})$, since $\mathrm{Cr}$ is known to decrease the hyperfine field while $\mathrm{Ni}$ is known to increase it [19]. This result agrees quite well with a similar annealing experiment which (by CEMS and XRD) found even a larger hyperfine field after a $64 \mathrm{~h}$ anneal at $400{ }^{\circ} \mathrm{C}$ [6]. It also agrees with an earlier XPS study, which indicated a surface $\mathrm{Cr}$ enhancement in a 316 SS (similar in composition to 304 SS) annealed at $400{ }^{\circ} \mathrm{C}$ [20].

The clear observation of $\alpha$ by CEMS in contrast to its relatively broad and weak signal by XRD (Fig. 1) can be explained by either a fine precipitate effect or a surface effect. In the first case, the precipitate size is such that it is detected clearly by CEMS (a local atomicscale probe), but not so clearly by XRD due to the peak broadening effect of small crystallites. The surface effect has to do with the fact that the $\alpha$ phase is localized at, or very near to, the surface which is seen by CEMS because of its much better near-surface sensitivity compared to XRD. Although the formation of the $\alpha-(\mathrm{Fe}, \mathrm{Ni})$ phase suggests $\mathrm{Cr}$ segregation, there is no clear evidence of $\mathrm{CrN}$ formation after $36 \mathrm{~h}$ anneal at $400{ }^{\circ} \mathrm{C}$ (this study), and even after $64 \mathrm{~h}$ at $400{ }^{\circ} \mathrm{C}$ (see Öztürk and Williamson [6]) (i.e. no $\mathrm{CrN}$ peaks near 38 and $64^{\circ}$ in the XRD patterns). This finding is also supported by $\mathrm{Li}$ et al. [8] (an isothermal annealing study of low-temperature plasma nitrided stainless steel), which (by XRD and TEM) found no chromium nitrides even after 60 and $100 \mathrm{~h}$ anneals at $400{ }^{\circ} \mathrm{C}$ (the specimens in this study were nitrided at $400{ }^{\circ} \mathrm{C}$ for $20 \mathrm{~h}$ ). However, the $\gamma_{\mathrm{N}}$ phase formed during low-temperature plasma nitriding was totally decomposed into $\mathrm{CrN}$ as a result of 600 ${ }^{\circ} \mathrm{C} / 20 \mathrm{~h}$ anneal [8]. The isothermal transformation diagram constructed as a result of this study finds the decomposition of the $\gamma_{\mathrm{N}}$ phase into the stable phase of $\mathrm{CrN}$ to be time- and temperature-dependent, i.e. while the $\gamma_{\mathrm{N}}$ phase decomposes within several minutes at temperatures higher than $500{ }^{\circ} \mathrm{C}$, it will not decompose even after thousands of hours at temperatures lower than $350{ }^{\circ} \mathrm{C}[8]$.

Supplemental data were obtained by CXMS, which show both magnetic and paramagnetic $\gamma_{\mathrm{N}}\left(\gamma_{1}\right.$ component only) resonances, and finds that the magnetic $\gamma_{\mathrm{N}}$ phase has a distribution range of approximately $0.8 \mu \mathrm{m}$ into the implanted layer (see Williamson et al. [18] for quantitative CXMS analysis). This observation correlates well with the results of another sample implanted under similar conditions which showed the $\gamma_{\mathrm{N}}(\mathrm{m})$ to exist within the top $1 \mu \mathrm{m}$ of the implanted layer [3]. The CXMS total $\gamma_{\mathrm{N}}$ resonance fraction (32\%) predicts a depth of approximately $1.5 \mu \mathrm{m}$ for the N-containing layer, which correlates well with the XRD depths. The CXMS spectrum after the $1 \mathrm{~h}$ anneal at $400{ }^{\circ} \mathrm{C}$ indicates the $\gamma_{\mathrm{N}}(\mathrm{m})$ phase extending to approximately $0.6 \mu \mathrm{m}$, but with a reduced hyperfine field and isomer shift. The CXMS results for the longer annealing steps are consistent with further diffusion of $\mathrm{N}$ into the substrate [21].

\section{Conclusions}

Post-ion beam processing via annealing experiments, done to examine the thermal stability of the low-energy, high-flux $\mathrm{N}$ implantation-induced near-surface phases and to induce further diffusion of the $\mathrm{N}$ in the absence of the ion beam, showed that the magnetic $\gamma_{\mathrm{N}}$ phase was destabilized as a result of annealing at $400{ }^{\circ} \mathrm{C}$, thereby resulting in thicker and predominantly paramagnetic $\gamma_{\mathrm{N}}$ layers with less $\mathrm{N}$ in solution and less lattice expansion. Based on XRD data, the $\mathrm{N}$ diffusivity in the absence of the $\mathrm{N}$ ion beam was estimated to be $\sim 10^{-13} \mathrm{~cm}^{2} / \mathrm{s}$ at $400{ }^{\circ} \mathrm{C}$, two to three orders of magnitude higher than that in fcc-SS with low $\mathrm{N}$ content, but too small by approximately two orders of magnitude to explain the $\mathrm{N}$ diffusivity during the low-energy, highflux $\mathrm{N}$ ion implantation into 304 SS. The higher diffusivity found here is attributed to the large $\mathrm{N}$ content of the $\gamma_{\mathrm{N}}$ phase in the as-implanted state (approx. 26 at.\%) and to the role played by the substrate element $\mathrm{Cr}$, the 
trapping by which is less effective when the $\mathrm{N}$ contents are high.

Although there is no decomposition into $\mathrm{CrN}$ at 400 ${ }^{\circ} \mathrm{C}$, which would be associated with poor corrosion resistance, the dramatic reduction in $\mathrm{N}$ content due to in and out diffusion has led to disappearance of the magnetic state of the $\gamma_{N}$ and a much thicker $\gamma_{N}$ layer. This behavior will be of significant relevance involving possible magnetic/tribological/corrosion-resistant applications of such surfaces that may reach this temperature in service.

\section{Acknowledgments}

The authors would like to thank the group of P.J. Wilbur of Colorado State University for performing the ion implantation. This project was funded by the National Science Foundation of the USA through grants MSS9116935 and MSS-9104480.

\section{References}

[1] D.L. Williamson, P.J. Wilbur, F.R. Fickett, S. Parascandola, in: T. Bell, K. Akamatsu (Eds.), Thermochemical Surface Engineering of Stainless Steels, IOM, London, 2001, in press.

[2] D.L. Williamson, J.A. Davis, P.J. Wilbur, J.J. Vajo, R. Wei, J.N. Matossian, Nucl. Instrum. Methods Phys. Res. B 127/128 (1997) 930.

[3] O. Öztürk, D.L. Williamson, J. Apply. Phys. 77 (1995) 3839.
[4] D.L. Williamson, O. Öztürk, R. Wei, P.J. Wilbur, Surf. Coatings Technol. 65 (1994) 15.

[5] R. Wei, B. Shogrin, P.J. Wilbur, et al., J. Tribol. 116 (1994) 870.

[6] O. Öztürk, D.L. Williamson, Hyperfine Interact. 92 (1994) 1329.

[7] D.L. Williamson, L. Wang, R. Wei, P.J. Wilbur, Mater. Lett. 9 (1990) 27.

[8] X.-Y. Li, Y. Sun, T. Bell, Z. Metallkd. 90 (1999) 901.

[9] K. Ichii, K. Fujimura, T. Takase, Technol. Rep. Kansai Univ. 127 (1986) 134.

[10] N. Narita, C.J. Altstetter, H.K. Birnbaum, Metall. Trans. A 13 (1982) 1355.

[11] M.P. Fewell, D.G.R. Mitchell, J.M. Priest, K.T. Short, G.A. Collins, Surf. Coatings Technol. 131 (2000) 300.

[12] D.L. Williamson, I. Ivanov, R. Wei, P.J. Wilbur, Mater. Res. Soc. Symp. Proc. 235 (1992) 473.

[13] S. Parascandola, W. Moller, D.L. Williamson, Appl. Phys. Lett. 76 (2000) 2194.

[14] K.H. Jack, Proc. R. Soc. A 208 (1951) 200.

[15] J. Hirvonen, A. Anttila, Appl. Phys. Lett. 64 (1985) 835.

[16] D. Fink, M. Muller, L. Wang, et al., Rad. Effects Defects Solids 115 (1990) 121.

[17] I.L. Singer, Vacuum 34 (1984) 853.

[18] D.L. Williamson, F.M. Kustas, D.F. Fobare, M.S. Misra, J. Appl. Phys. 60 (1986) 1493.

[19] S. Nagy, E. Kuzmann, A. Vertes, G. Szabo, G. Konczos, Nucl. Instrum. Methods B 34 (1988) 217.

[20] P. Gronin, S. Novak, L. Schlapbach, Appl. Surf. Sci. 52 (1991) 333.

[21] O. Öztürk, Ph.D. Thesis no. 4489, Colorado School of Mines, 1994. 